\title{
Outbreak of Middle East respiratory syndrome coronavirus in Saudi Arabia: a retrospective study
}

\author{
Fadilah Sfouq Aleanizy ${ }^{1 *}$, Nahla Mohmed², Fulwah Y. Alqahtani and Rania Ali El Hadi Mohamed ${ }^{3,4}$
}

\begin{abstract}
Background: The Middle East respiratory syndrome (MERS) is proposed to be a zoonotic disease. Dromedary camels have been implicated due to reports that some confirmed cases were exposed to camels. Risk factors for MERS coronavirus (MERS-CoV) infections in humans are incompletely understood. This study aimed to describe the demographic characteristics, mortality rate, clinical manifestations and comorbidities with confirmed cases of MERS-CoV.

Methods: Retrospective chart review were performed to identify all laboratory-confirmed cases of MERS-CoV in Saudi Arabia who reported to the Ministry of Health (MOH) of Saudi Arabia and WHO between April 23, 2014 and August 31, 2015. Patients' charts were also reviewed for demographic information, mortality, comorbidities, clinical presentations, health care facility and presented with descriptive and comparative statistics using non parametric binomial test and Chi-square test.
\end{abstract}

Results: Confirmed cases of male patients (61.1\%) exceeded those of female patients (38.9\%). Infections among Saudi patients (62.6\%) exceeded those among non-Saudi patients (37.4\%; $P=0.001)$. The majority of the patients were aged 21-40 years (37.4\%) or 41-60 years (35.8\%); 43 (22.6\%) were aged $>61$ years, and (8) 4.2\% were aged $0-20$ years. There was a difference in mortality between confirmed MERS-CoV cases (63.7\% alive versus $36.3 \%$ dead cases, respectively). Furthermore, fever with cough and shortness of breath (SOB) $(n=39 ; 20.5 \%)$, fever with cough $(n=29 ; 15.3 \%)$, fever $(n=18 ; 9.5 \%)$, and fever with SOB $(n=13 ; 6.8 \%)$, were the most common clinical manifestations associated with confirmed MERS-CoV cases.

Conclusion: MERS-CoV is considered an epidemic in Saudi Arabia. The results of the present study showed that the frequency of cases is higher among men than women, in Saudi patients than non-Saudi, and those between 21 to 60 years are most affected. Further studies are required to improve the surveillance associated with MERS-CoV to get definite and clear answers and better understanding of the MERS-CoV outbreak as well the source, and route of infection transmission in Saudi Arabia.

Keywords: Middle East respiratory syndrome, Epidemiology, Saudi Arabia

\section{Background}

Coronaviruses are large enveloped viruses with a singlestranded positive-sense RNA genome. They can infect humans, as well as a variety of animals, such as bats, mice, birds, dogs, pigs, and cattle, causing mainly respiratory and enteric diseases [1]. The virus MERS-CoV is a new member of the beta group of coronavirus, Beta

\footnotetext{
* Correspondence: faleanizy@ksu.edu.sa

${ }^{1}$ College of Pharmacy, Department of Pharmaceutics, King Saud University,

22452, Riyadh 11495, Saudi Arabia

Full list of author information is available at the end of the article
}

coronavirus. MERS-CoV is different from SARS coronavirus and different from the common-cold coronavirus and known as endemic human betacoronaviruses $\mathrm{HCoV}-\mathrm{OC} 43$ and HCoV-HKU1. MERS-CoV had frequently been referred to as a SARS-like virus, or the novel coronavirus until 23 May 2013. On September 11, 2012, a 49-year-old man from Qatar, with a history of travel to Saudi Arabia, was transferred to the United Kingdom with symptoms of severe respiratory illness. Sample from the lower respiratory tract samples of the patient was found positive after a pancoronavirus RT-PCR assay. Comparison of the sequence of 
the PCR fragments with the ones obtained in the case of the Saudi patient revealed that they share 99\% similarity, suggesting infection by the same virus [1]. Sequencing of the novel coronavirus was performed at the Erasmus Medical Center (EMC) in Rotterdam, the Netherlands, where the virus was named "human coronavirus EMC" (hCoV-EMC) [2]. Later, the Coronavirus Study Group of the International Committee on Taxonomy of Viruses renamed the virus "Middle East respiratory syndrome coronavirus" (MERS-CoV) in May 2013 [3].

MERS-CoV is a zoonotic virus that is transmitted from animals that are a reservoir of the virus to humans. Although the source of MERS-COV is not elucidated yet, camels are the most likely source of infection in human $[3,4]$. A coronavirus similar to large extent to the one detected in humans has been isolated from camels in Egypt, Oman, Qatar, and Saudi Arabia. Other animals including goats, cows, sheep, water buffalo, swine, and wild birds, have been tested for MERS-CoV and only dromedary camels have evidence of sero-positivity to MERS-COV, supporting the premise that dromedary camels are a likely source of infection in humans [3].

Direct contact with the saliva of infected camels, or consumption of contaminated milk or meat was the suspected transmission route for human MERS-COV infection [4]. Previous study found that the seroprevalence of MERS-CoV was several times higher in persons with regular exposure to camels than in the general population $[5,6]$. However, there are some cases infection in which the patients do not have any contact with sick animals or their products. This might be human to human route of transmission.

Only limited numbers of zoonotic diseases have been reported to be transmitted from human to human [7]. The incapability of MERS-CoV to infect animal models like hamsters, mice, and ferrets, indicates the presence of a species barrier. However, an experimental study showed that human cell lines were susceptible to MERS-CoV infection [8], and the reports of human-to-human transmission have increased [9-11]. The modes of human-tohuman MERS-CoV spread are incompletely defined [12].

Emergence of the Middle East respiratory syndrome coronavirus (MERS-CoV) has caused significant concern. A total of 635 laboratory-confirmed cases of MERS-CoV infection have been reported globally, including 193 deaths. Cases of MERS-CoV in Saudi Arabia were reported for the first time in September 2012, following the death of a patient due to a severe respiratory illness [13-15]. Little is known regarding the extent of human infection or the degree of detection bias towards more severe cases. If the severe cases currently being detected represent only a small sentinel minority of a much larger population of milder cases (as occurred in the early stage of the $2009 \mathrm{H} 1 \mathrm{~N} 1$ pandemic in Mexico) [16], the case- fatality ratio might be substantially lower than what current surveillance data suggest. Conversely, for the severe acute respiratory syndrome (SARS) epidemic of 2003, there was little evidence of the existence of undetected mild or subclinical infections [17-20].

Risk factors for the disease in humans are incompletely understood [21], although MERS is proposed to be a zoonotic disease. Dromedary camels have been implicated due to reports that some confirmed cases were exposed to camels. In the Middle East, confirmed cases of MERS-CoV have arisen as sporadic, familial, or hospital clusters [13, 22-26]. Although human-to-human transmission of MERS-CoV has been identified in many European, African, and Middle Eastern countries, [27-30] a genomic analysis of the Riyadh MERS-CoV isolates suggested that there were three genetically distinct lineages of MERS-CoV; therefore, it was unlikely that the Riyadh infections were the result of a single, continuous chain of human-to-human transmission [15, 31, 32]. A recent study provided further evidence of non-sustainable transmission among humans and suggested that transmission within Saudi Arabia was dependent on contact with an animal reservoir or animal products [14]; however, no animal reservoir has yet been identified. While contact with camels has been reported, these reports were limited to only the primary cases [22, 33-37]. The MERS-CoV was related with a strain of severe acute respiratory syndrome coronavirus (SARS-CoV) that caused an outbreak in 29 countries in 2002-2003. This outbreak was characterized by 8273 cases and 775 deaths, with the majority of cases in Hong Kong [16]. As was determined for the SARS-CoV during its pre-pandemic stage, the MERS$\mathrm{CoV}$ has likely been repeatedly transmitted from an unknown animal host to humans in the past year [17-20].

To obtain effective control of the MERS-CoV outbreak, the MOH of the Kingdom of Saudi summoned a Rapid Response Team (RRT). The RRT was composed of 15 infectious disease doctors and two infection control professionals affiliated with the Korean Society for Infectious Diseases and the Korean Society for Healthcare-associated Infection Control and Prevention. The RRT established national infection control and prevention guidelines for the diagnosis and management of MERS-CoV infections [32, 38-41]. The current study aimed to investigate the demographic characteristics, history of contact with camels or positive cases, mortality, clinical manifestation and comorbidities for confirmed cases of MERS-CoV.

\section{Methods}

Data collection

All laboratory confirmed MERS-CoV cases who were reported by the Saudi Ministry of Health to WHO from April 23, 2014 to August 31, 2015, were identified. 
Patient's charts were reviewed for demographic information, mortality, comorbidities, clinical presentations and health care facility.

\section{Case definition}

A confirmed case was defined as any person with laboratory confirmation of MERS-CoV infection based on positive real-time polymerase chain reaction (PCR) of MERS$\mathrm{CoV}$ in swab samples collected by the $\mathrm{MOH}$ in addition to any one of the following clinical definitions: fever $\left(>38^{\circ} \mathrm{C}\right)$, a cough, shortness of breath (SOB), sore throat, vomiting, diarrhea, hemoptysis, chest pain and/or infection, respiratory failure, loss of consciousness, runny nose and any asymptomatic outpatients with a history of contact with positive symptomatic cases and tested positive. Patients provided their signed consent to publication where legal guardian provided consent for a minor.

\section{Molecular testing}

All PCR testing was carried out at the Saudi Ministry of Health MERS-CoV regional laboratory in Riyadh. Respiratory samples were obtained from all patients and submitted to the regional lab to be tested for MERS-COV infection using primers that amplify both the upstream E protein (upE) and ORF1a genes. Samples that tested positive for both upE and Orf 1a gene targets were considered confirmed cases. Each patient was tested at least twice, each on a different day.

\section{Statistical analysis}

Differences were assessed for significance using chi-square goodness of fit and non-parametric binomial tests, where appropriate. Statistical analyses were performed using SPSS, version 21 software (IBM Corp., Armonk, NY, USA). $P<0.05$ was considered statistically significant.

\section{Results}

As is shown in Table 1, the confirmed male-to-female case ratio was 1.6:1. There were significantly more infections among Saudi patients than among non-Saudi patients $(62 \%$ versus $37.4 \% ; P=0 \cdot 001$; Table 1$)$. Of the 190 patients, $141(74.2 \%)$ had no history of contact with camels or positive cases. A total of 147 (73.2\%) patients were aged 20-60 years. The lowest percentage of patients was younger than 20 years of age. Of the 190 patients with confirmed MERS-CoV infection, 69 patients (36.3\%) died and 121 patients (63.7\%) lived (Table 2). The most common symptoms at presentation were (fever, cough, SOB) ( $n=39 ; 20.5 \%)$, (fever, cough) $(n=29 ; 15.3 \%)$, fever $(n=18 ; 9.5 \%)$, (fever, SOB) $(n=13 ; 6.8 \%),(\mathrm{SOB}$, cough) $(n=6 ; 3.2 \%)$, and Respiratory Failure $(n=3 ; 1.6 \%)$ (Fig. 1). Other symptoms were reported less frequently by $5 \%$ of patients including chest infection; cold, cough, SOB; cough, diarrhea; cough, SOB, hemaptisis; fever, cough,
Table 1 Demographic characteristics of Middle East respiratory syndrome coronavirus cases in Saudi Arabia between April 23, 2014 and August 31, 2015

\begin{tabular}{lll}
\hline Variable & Confirmed Cases $(n=190)$ & P-value \\
\hline Sex & $116(61.1)$ & 0.003 \\
M & $74(38.9)$ & \\
F & & $<0.0001$ \\
groups Age & $8(4.2)$ & \\
$21-40$ & $71(37.4)$ & \\
$41-60$ & $68(35.8)$ & 0.001 \\
$\geq 61$ & $43(22.6)$ & \\
Nationality & $119(62.6)$ & $<0.0001$ \\
Saudi & $71(37.4)$ & \\
Non-Saudi & & \\
History of contact & $1(0.5)$ & \\
Camels or & $48(25.3)$ & \\
positive case & $141(74.2)$ & \\
None & & \\
\hline
\end{tabular}

Data are $\mathrm{n}(\%)$

SOB, vomiting and cough, SOB. All 27 asymptomatic patients (14.2\% of 190$)$ with a history of contact with positive symptomatic cases were tested positive (Fig. 1).

Figure 2 presents frequency and distribution of the confirmed cases that were admitted to health facilities from different provinces in Saudi Arabia. In Riyadh, the majority of cases were reported from the Eastern region of Riyadh (113 cases, (59.5\%)). 29 cases (15.3\%) from Central region of Riyadh, 15 cases (7.9\%) from North region in Riyadh, 12 cases (6.3\%) from South region of Riyadh and 4 cases $(2.1 \%)$ from West region in Riyadh. On the other hand, 16 cases $(8.4 \%)$ collectively reported from other provinces in Saudi Arabia. Of the 190 patients, 108 (56.8\%) had underlying medical disorders, and $82(43.2 \%)$ were previously healthy (Table 3 ). Diabetes 60 (31.6\%), hypertension 54 (28.4\%) and bronchial asthma 18 (9.5\%) were the most frequent comorbid disorders (Table 3).

\section{Discussion}

Of the 190 (116 men and 74 women) confirmed cases of MERS-CoV infection in our study, only a single patient

Table 2 Mortality rates of confirmed versus suspected cases of Middle East respiratory syndrome coronavirus between April 23, 2014 and August 31, 2015

\begin{tabular}{lll}
\hline Outcome & Confirmed & $P$-value \\
\hline Survival & $121(63.7)$ & $<0.0001$ \\
Death & $69(36.3)$ & \\
Total & 190 &
\end{tabular}

Data are $\mathrm{n}(\%)$ 


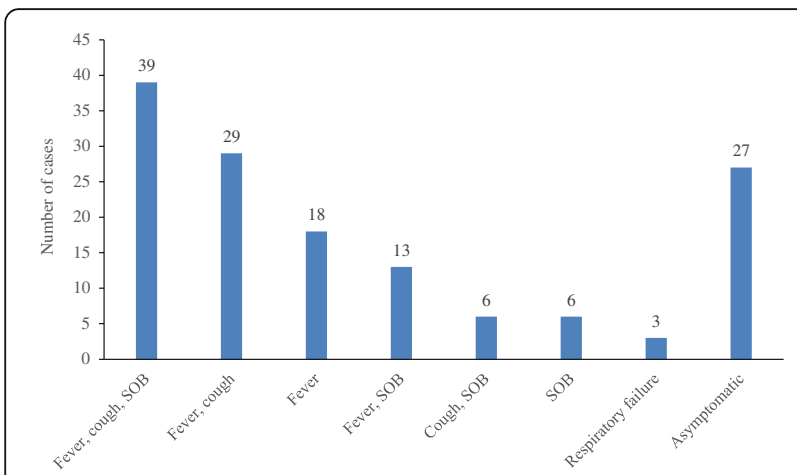

Fig. 1 Clinical manifestations of patients with confirmed Middle East respiratory syndrome coronavirus $(n=190)$ between April 23, 2014 and August 31, 2015 had a history of direct contact with camels and 48 had direct contact with positive cases of MERS-CoV; 141 patients did not have any contact with camels and other sick patients. An analysis of the demographic characteristics of the confirmed cases of MERS-CoV during the 18-month study period demonstrated that only eight cases were patients aged $<20$ years; $73.2 \%$ of the cases were patients aged $21-60$ years, and $22.6 \%$ of the cases were patients aged $>61$ years. Notably, a high number (37.4\%) of the confirmed cases of MERS-CoV were not of Saudi nationality.

The respiratory clinical manifestations of MERS-CoV infection for all of the patients in the present study were similar to those observed in previous studies of other Saudi patients from different regions in Saudi Arabia. Fever with cough and SOB, then fever with cough were the most common symptoms among patients $(20.5 \%$

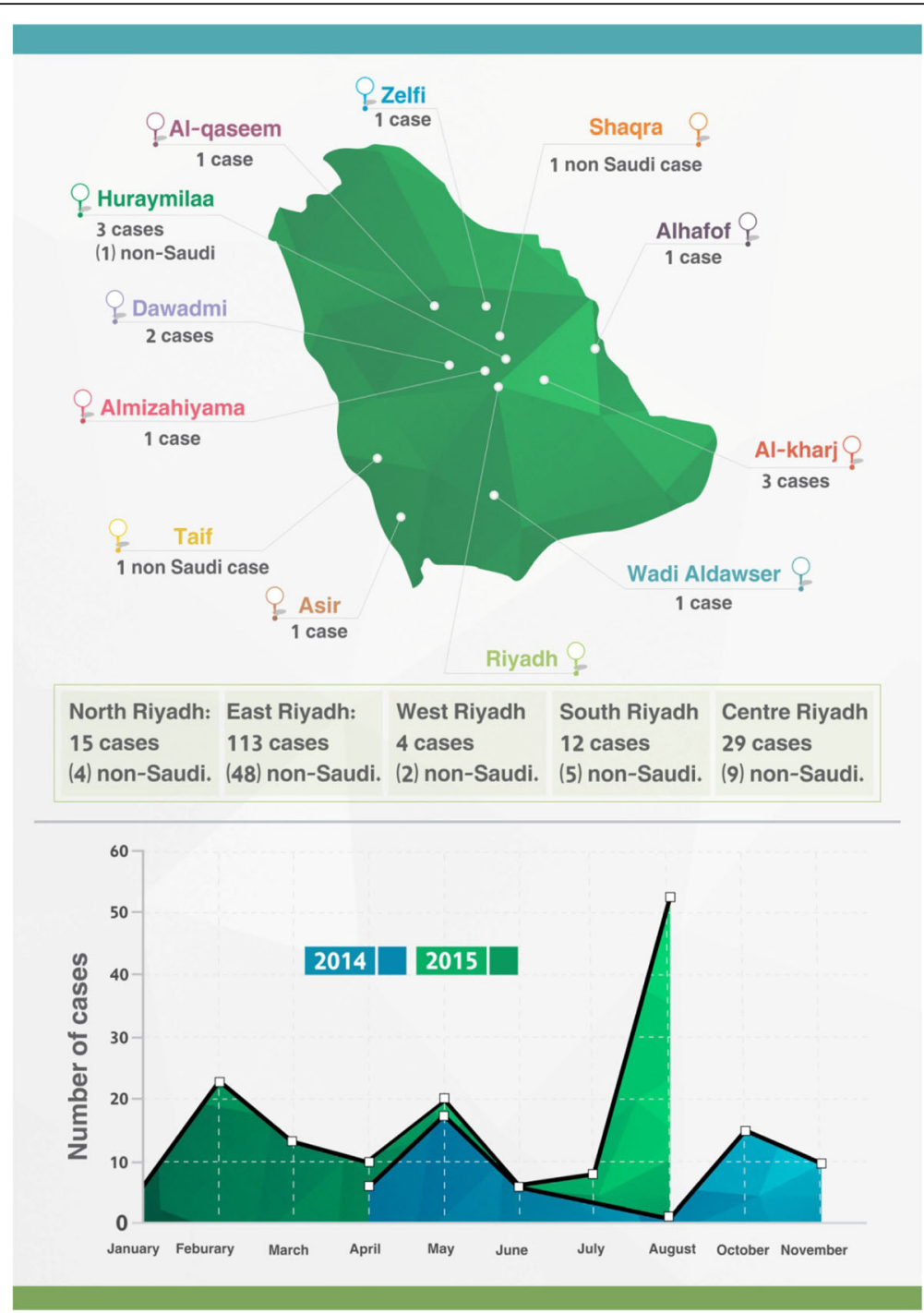

Fig. 2 Distributions of Middle East respiratory syndrome coronavirus cases in Saudi Arabia between April 23, 2014 and August 31, 2015 
Table 3 Frequency of comorbidities in patients with confirmed Middle East respiratory syndrome coronavirus

\begin{tabular}{ll}
\hline Comorbidities & Patients \\
\hline Diabetes mellitus & $60(31.6)$ \\
Hypertension & $54(28.4)$ \\
B. asthma & $18(9.5)$ \\
IHD & $11(5.8)$ \\
CHF & $5(2.6)$ \\
End-stage renal disease & $5(2.6)$ \\
Pneumonia & $4(2.1)$ \\
Hypothyroidism & $4(2.1)$ \\
CVA & $3(1.6)$ \\
Liver cirrhosis & $2(1.1)$ \\
HF & $1(0.5)$ \\
BPH & $1(0.5)$ \\
Hodgkin's lymphoma & $1(0.5)$ \\
Chronic obstructive pulmonary disease & $1(0.5)$ \\
Sickle cell anemia & $1(0.5)$ \\
Liver carcinoma & $1(0.5)$ \\
Mitral + aortic valve replacement & $1(0.5)$ \\
Acute respiratory distress syndrome & $1(0.5)$ \\
Chronic kidney disease & $1(0.5)$ \\
Tuberculosis & $1(0.5)$ \\
RF & $1(0.5)$ \\
CP & $1(0.5)$ \\
COPC & $1(0.5)$ \\
Lung cancer & $1(0.5)$ \\
Anemia & $1(0.5)$ \\
Myeloma & $1(0.5)$ \\
None & $1(0.5)$ \\
Data are n (\%) & $82(43.2)$ \\
\hline
\end{tabular}

and $15.3 \%$, respectively). These findings are consistent with previous reports [21, 22, 38, 42-47].

Notably, the clinical features of MERS-CoV infection ranged from asymptomatic or mild disease to acute respiratory distress syndrome and multi-organ failure, which is consistent with the findings of previous studies from various countries [33, 34, 40, 43, 47, 48]. To date, only three studies have reported the clinical characteristics and outcomes of patients with MERS-CoV infection who were admitted to the intensive care unit (ICU), which collectively included 34 patients [44-47, 49, 50]. Arabi et al. analyzed data for 12 patients admitted to two ICUs in Riyadh and one in Al-Hasa in the central and eastern parts of the country, respectively [47]. The remaining two reports were both from Jeddah in Western Saudi Arabia. The study by Al-Hameed et al. included eight patients [44], whereas Khalid et al. described the clinical course and outcomes of 14 patients with severe MERS-CoV infection [50].

There is a need to improve the collaboration between scientific researchers, clinical units, and public health communities in order to provide an effective community health service and to prepare for future outbreaks of MERS-CoV, to ultimately decrease the number of new cases [22, 29, 35, 47, 48]. The MERS-CoV outbreak in Saudi Arabia appeared to be reaching controlled levels, with a significant decrease in the number of new cases. Furthermore, there were no new super spreading events that could result in a third epidemic peak. Vigilant monitoring will be crucial to end the MERS-CoV outbreak. The RRT hopes to share their knowledge of the MERS-CoV outbreak with other countries and to cooperate in the prevention of the MERS-CoV outbreak from becoming a global pandemic.

\section{Conclusion}

MERS-CoV is considered an epidemic in Saudi Arabia. The results of the present study showed that the frequency of cases is higher among men than women, in Saudi patients than non-Saudi, and those between 21 to 60 years are most affected. Furthermore, Eastern Region of Riyadh had the highest number of cases. However, further studies are required to determine association of demographic characteristics with mortality, source, and route of infection transmission in Saudi Arabia. We recommend that much more studied are remains to be discovered about MERS-CoV. Improved surveillance, epidemiological research for the development of new therapies and vaccine are important for both human and camels. Further studies are required to gains in terms of better understanding of disease patterns should be maintained to enable the global community to answer the remaining questions about this disease.

\section{Abbreviations}

ICU: Intensive care unit; MERS: the Middle East respiratory syndrome; $\mathrm{MOH}$ : Ministry of Health; RRT: Rapid Response Team; SARS: Severe acute respiratory syndrome; WHO: World Health Organization

\section{Funding}

The study was supported by the Research Centre of the Science and Medical studies Departments at King Saud University.

\section{Availability of data and materials}

Data supporting the findings are included in the manuscript.

\section{Authors' contributions}

FA carried out the study design, data management, and data analysis, and helped to draft the manuscript. NM, FAI, RM analyzed the data and drafted the manuscript. All authors read and approved the final manuscript.

\section{Competing interests}

The authors declare that they have no competing interests. 


\section{Consent for publication}

Not applicable.

\section{Ethics approval and consent to participate}

This investigation was part of an emergency public health response and was determined to be non-research by $\mathrm{MoH}$ and therefore not subject to institutional review board review.

\section{Author details}

'College of Pharmacy, Department of Pharmaceutics, King Saud University, 22452, Riyadh 11495, Saudi Arabia. ${ }^{2}$ College of Medicine, Princess Nourah Bint Abdulrahman University, Riyadh 12484, Saudi Arabia. ${ }^{3}$ College of Science, Princess Nourah Bint Abdulrahman University, Riyadh 12484, Saudi Arabia. ${ }^{4}$ Scientific research, Federal Ministry of Health, Khartoum 303, Sudan

\section{Received: 12 August 2016 Accepted: 17 December 2016}

Published online: 05 January 2017

\section{References}

1. Bermingham A, et al. Severe respiratory illness caused by a novel coronavirus, in a patient transferred to the United Kingdom from the Middle East, September 2012. Euro Surveill. 2012;17:20290.

2. Van Boheemen S. et al. Genomic characterization of a newly discovered coronavirus associated with acute respiratory distress syndrome in humans. MBio. 2012:3:1-9.

3. De Groot RJ, et al. Middle East respiratory syndrome coronavirus (MERS-CoV): announcement of the Coronavirus Study Group. J Virol. 2013;87:7790-2.

4. Durai P, Batool M, Shah M, Choi S. Middle East respiratory syndrome coronavirus: transmission, virology and therapeutic targeting to aid in outbreak control. Exp Mol Med. 2015:47:e181.

5. Kayali G, Peiris M. A more detailed picture of the epidemiology of Middle East respiratory syndrome coronavirus. Lancet Infect Dis. 2015;15:495-7.

6. Müller MA, Meyer B, Corman VM, Al-Masri M, Turkestani A, Ritz D, Sieberg A, Aldabbagh S, Bosch BJ, Lattwein E, Alhakeem RF, Assiri AM, Albarrak AM, AlShangiti AM, Al-Tawfiq JA, Wikramaratna P, Alrabeeah AA, Drosten C, Memish ZA. Presence of Middle East respiratory syndrome coronavirus antibodies in Saudi Arabia: a nationwide, cross-sectional, serological study. Lancet Infect Dis. 2015;15:629.

7. Weber DJ, Rutala WA. Risks and prevention of nosocomial transmission of rare zoonotic diseases. Clin Infect Dis. 2001;32:446-56.

8. Van Doremalen N, Miazgowicz KL, Milne-Price S, Bushmaker T, Robertson S, Scott D, Kinne J, Mc-Lellan JS, Zhu J, Munster VJ. Host species restriction of Middle East respiratory syndrome coronavirus through its receptor, dipeptidyl peptidase 4. J Virol. 2014;88:9220-32.

9. Assiri A, McGeer A, Perl TM, Price CS, Al Rabeeah AA, Cummings DA, Alabdullatif ZN, Assad M, Almulhim A, Makhdoom H, Madani H, Alhakeem R, Al-Tawfiq JA, Cotten M, Watson SJ, Kellam P, Zumla Al, Memish ZA, KSA MERS-CoV Investigation Team. Hospital outbreak of Middle East respiratory syndrome coronavirus. N Engl J Med. 2013;369:407-16.

10. Assiri A, Al-Tawfiq JA, Al-Rabeeah AA, Al-Rabiah FA, Al-Hajiar S, Al-Barrak A Flemban H, Al-Nassir WN, Balkhy HH, Al-Hakeem RF, Makhdoom HQ, Zumla Al, Memish ZA. Epidemiological, demographic, and clinical characteristics of 47 cases of Middle East respiratory syndrome coronavirus disease from Saudi Arabia: a descriptive study. Lancet Infect Dis. 2013;13:752-61.

11. Mailles A, Blanckaert K, Chaud P, van der Werf S, Lina B, Caro V, Campese C, Guéry B, Prouvost H, Lemaire X, Paty MC, Haeghebaert S, Antoine D, Ettahar N, Noel H, Behillil S, Hendricx S, Manuguerra JC, Enouf V, La Ruche G, Semaille C, Coignard B, Lévy-Bruhl D, Weber F, Saura C, Che D. investigation team. First cases of Middle East Respiratory Syndrome Coronavirus (MERS-CoV) infections in France, investigations and implications for the prevention of human-tohuman transmission, France, May 2013. Euro Surveill. 2013;18:pii:20502

12. Perlman S, McCray Jr PB. Person-to-person spread of the MERS coronavirusan evolving picture. N Engl J Med. 2013;369:466-7.

13. Alraddadi BM, Watson JT, Almarashi A, et al. Risk factors for primary Middle East respiratory syndrome coronavirus illness in humans, Saudi Arabia, 2014. Emerg Infect Dis. 2016;22:49-55.

14. Memish ZA. Brief report: Family cluster of Middle East respiratory syndrome coronavirus infections (vol 368, pg 2487, 2013). N Engl J Med. 2013:369:587.

15. Al-Tawfiq JA, Hinedi $K$, Ghandour J, et al. Middle East respiratory syndrome coronavirus: a case-control study of hospitalized patients. Clin Infect Dis. 2014;59:160-5.
16. Hawkes N. Camels could be the source of MERS coronavirus, research finds. BMJ. 2013:347:f5052

17. Zaki AM, van Boheemen S, Bestebroer TM, Fouchier RAM. Isolation of a novel coronavirus from a man with pneumonia in Saudi Arabia. N Engl J Med. 2012;367:1814-20.

18. Memish ZA, Zumla Al, Al-Hakeem RF, Al-Rabeeah AA, Stephens GM. Family cluster of Middle East respiratory syndrome coronavirus infections. N Engl J Med. 2013;368:2487-94.

19. Abroug F, Slim A, Ouanes-Besbes, et al. Family cluster of Middle East respiratory syndrome coronavirus infections, Tunisia, 2013. Emerg Infect Dis. 2014:20:1527-30.

20. Cotton M, Watson SJ, Kellam P, et al. Transmission and evolution of the Middle East respiratory syndrome coronavirus in Saudi Arabia: a descriptive genomic study. Lancet. 2013;382:1993-2002

21. Al-Tawfiq JA, Omrani AS, Memish ZA. Middle East respiratory syndrome coronavirus: current situation and travel-associated concerns. Front Med. 2016;10:111-9.

22. Leblebicioglu H, Rodriquez-Morales AJ, Rossolini GM, et al. Management of infections in critically ill returning travellers in the intensive care unit-l: considerations on infection control and transmission of resistance. Int J Infect Dis. 2016:48:113-7.

23. Ki CS, Lee $H$, Sung $H$, et al. Korean Society for Laboratory Medicine practice guidelines for the molecular diagnosis of Middle East respiratory syndrome during an outbreak in Korea in 2015. Ann Lab Med. 2016;36:203-8.

24. Yousefi M, Dehesh MM, Farokhnia M. Epidemiological and clinical characteristics of patients with Middle East respiratory syndrome coronavirus in Iran in 2014. Jpn J Infect Dis. 2016.

25. Pavli A, Tsiodras S, Maltezou HC. Middle East respiratory syndrome coronavirus (MERS-CoV): prevention in travelers. Travel Med Infect Dis. 2014;12:602-8.

26. Chu DK, Oladipo JO, Perera RA, et al. Middle East respiratory syndrome coronavirus (MERSCOV) in dromedary camels in Nigeria, 2015. Euro Surveill. 2015;20:11-7.

27. Corman VM, Jores J, Meyer B, et al. Antibodies against MERS coronavirus in dromedary camels, Kenya, 1992-2013. Emerg Infect Dis. 2014;20:1319-22.

28. Memish Z, Al-Tawfiq JA, Makhdoom JA, et al. Screening for Middle East respiratory syndrome coronavirus infection in hospital patients and their healthcare worker and family contacts: a prospective descriptive study. Clin Microbiol Infect. 2014;20:469-74.

29. Alagaili AN, Briese T, Mishra N, et al. Middle East respiratory syndrome coronavirus infection in dromedary camels in Saudi Arabia. MBio. 2014;5:e00884-14.

30. Chu DK, Poon LLM, Gomaa MM, et al. MERS coronaviruses in dromedary camels, Egypt. Emerg Infect Dis. 2014;20:1049-53.

31. Memish ZA, Cotton M, Meyer B, et al. Human infection with MERS coronavirus after exposure to infected camels, Saudi Arabia, 2013. Emerg Infect Dis. 2014:20:1012-5.

32. Reusken C, Haagmans BL, Koopmans MP. [Dromedary camels and Middle East respiratory syndrome: MERS coronavirus in the 'ship of the desert']. Ned Tijdschr Geneeskd. 2014;158:A7806.

33. Yusof MF, Eltahir YM, Serhan WS, et al. Prevalence of Middle East respiratory syndrome coronavirus (MERS-CoV) in dromedary camels in Abu Dhabi Emirate, United Arab Emirates. Virus Genes. 2015;50:509-13.

34. Poon LL, Chan KH, Wong OK, et al. Detection of SARS coronavirus in patients with severe acute respiratory syndrome by conventional and real-time quantitative reverse transcription-PCR assays. Clin Chem. 2004:50:67-72.

35. Yam WC, Chan KH, Poon LL, et al. Evaluation of reverse transcription-PCR assays for rapid diagnosis of severe acute respiratory syndrome associated with a novel coronavirus. J Clin Microbiol. 2003:41:4521-4.

36. Poon LL, Chan $\mathrm{KH}$, Wong OK, et al. Early diagnosis of SARS Coronavirus infection by real time RT-PCR. J Clin Virol. 2003;28:233-8.

37. Lau LT, Fung YW, Wong FP, et al. A real-time PCR for SARS-coronavirus incorporating target gene pre-amplification. Biochem Biophys Res Commun. 2003;312:1290-6.

38. Wahla AS. Author's Response to Letter to Editor on "Characteristics and Outcomes of Middle East Respiratory Syndrome Coronavirus Patients Admitted to an Intensive Care Unit in Jeddah, Saudi Arabia". J Intensive Care Med. 2016:31:289.

39. Senga M, Arabi YM, Fowler RA. Clinical spectrum of the Middle East respiratory syndrome coronavirus (MERS-CoV). J Infect Public Health. 2016.

40. Alraddadi B, Bawareth $\mathrm{N}$, Omar $\mathrm{H}$, et al. Patient characteristics infected with Middle East respiratory syndrome coronavirus infection in a tertiary hospital. Ann Thorac Med. 2016;11:128-31. 
41. Al-Hameed F, Wahla AS, Siddiqui S, et al. Characteristics and outcomes of Middle East respiratory syndrome coronavirus patients admitted to an intensive care unit in Jeddah, Saudi Arabia. J Intensive Care Med. 2016:31:344-8.

42. Alqahtani SH, Aldawsari MN. Epidemiology and clinical presentation of MERSCoV in Saudi Arabia: a systematic review. Trop Med Int Health. 2015;20:268.

43. Saad M, Omrani AS, Baig K, et al. Clinical aspects and outcomes of 70 patients with Middle East respiratory syndrome coronavirus infection: a single-center experience in Saudi Arabia. Int J Infect Dis. 2014;29:301-6.

44. Arabi YM, Arifi AA, Balkhy HH, et al. Clinical course and outcomes of critically ill patients with Middle East respiratory syndrome coronavirus infection. Ann Intern Med. 2014;160:389-97.

45. Al-Abdallat MM, Payne DC, Alqasrawi S, et al. Hospital-associated outbreak of Middle East respiratory syndrome coronavirus: a serologic, epidemiologic, and clinical description. Clin Infect Dis. 2014;59:1225-33.

46. Korean Society of Infectious Diseases, Korean Society for Healthcareassociated Infection Control and Prevention. The same Middle East respiratory syndrome-coronavirus (MERS-CoV) yet different outbreak patterns and public health impacts on the far east expert opinion from the rapid response team of the Republic of Korea. Infect Chemother. 2015:47:247-51.

47. Khalid M, Khan B, Al Rabiah F, et al. Middle Eastern respiratory syndrome corona virus (MERS CoV): case reports from a tertiary care hospital in Saudi Arabia. Ann Saudi Med. 2014;34:396-400.

48. Petersen E, Pollack MM, Madoff LC. Health-care associate transmission of Middle East respiratory syndrome corona virus, MERS-CoV, in the Kingdom of Saudi Arabia. Int J Infect Dis. 2014;29:299-300.

49. Guery B, Poissy J, el Mansouf $L$, et al. Clinical features and viral diagnosis of two cases of infection with Middle East respiratory syndrome coronavirus: a report of nosocomial transmission. Lancet. 2013;381:2265-72.

50. Fitzpatrick F, Roche F, Cunney R, et al. Challenges of implementing national guidelines for the control and prevention of methicillin-resistant Staphylococcus aureus colonization or infection in acute care hospitals in the Republic of Ireland. Infect Control Hosp Epidemiol. 2009;30:277-81.

\section{Submit your next manuscript to BioMed Central and we will help you at every step:}

- We accept pre-submission inquiries

- Our selector tool helps you to find the most relevant journal

- We provide round the clock customer support

- Convenient online submission

- Thorough peer review

- Inclusion in PubMed and all major indexing services

- Maximum visibility for your research

Submit your manuscript at www.biomedcentral.com/submit 